\title{
FESTIVAIS GINÁSTICOS: PRINCÍPIOS FORMATIVOS NA VISÃO DE ESPECIALISTAS
}

Tamiris Lima Patrício, Universidade Estadual de Campinas - UNICAMP, Campinas, São

Paulo - Brasil

Marco Antonio Coelho Bortoleto, Universidade Estadual de Campinas - UNICAMP, Campinas, São Paulo - Brasil

\section{RESUMO}

Os Festivais Ginásticos consistem em eventos onde diversas possibilidades gímnicas são apresentadas visando o congraçamento e o intercâmbio entre seus praticantes. $\mathrm{O}$ objetivo deste trabalho foi discutir os princípios pedagógicos e formativos que norteiam os festivais ginásticos a partir da opinião de profissionais que atuam na organização deste tipo de evento, visando ainda, conhecer qual sua relevância para o fomento e manutenção da tradição ginástica. Para isso realizamos uma pesquisa de caráter qualitativo, consultando nove voluntários especialistas (Argentina, Brasil, Chile, Dinamarca, Espanha, México, Portugal e República Tcheca) por meio de um questionário semi-estruturado. Os resultados confirmam a importância que os festivais possuem tanto no campo da ginástica como para a formação humana, principalmente na manutenção das tradições gímnicas, na troca de experiências (técnicas e estéticas), no intercâmbio cultural e na valorização da participação, do voluntariado e da coletividade.

Palavras-Chave: Festival; Ginástica; Formação; Tradição; Educação.

\section{FESTIVALS GYMNASTIC: PRINCIPLES OF FORMATION IN VISION SPECIALISTS}

\begin{abstract}
Gymnastic Festivals are events where various gymnastic possibilities are presented aimed at fellowship and exchange between practitioners. The aim of this study was to discuss the educational and formation principles that guides the gymnastic festivals, through the eyes of professionals that works in the organization of this type of event, aiming also to know what is their relevance to the promotion and maintenance of gymnastic tradition. For this, we conducted a qualitative research by consulting nine expert volunteers (Argentina, Brazil, Chile, Denmark, Spain, Mexico, Portugal and the Czech Republic) through a semi-structured questionnaire. The results confirm the importance that festivals have as in the area of gymnastics to human formation, especially in the maintenance of gymnastic traditions, in the exchanging experiences (technical and aesthetical), in the cultural exchange and in the valorization of participation, volunteering and collectivity.
\end{abstract}

Key-Words: Festival; Gymnastics; Formation; Tradition; Education.

Conexões: revista da Faculdade de Educação Física da UNICAMP, Campinas, v. 13, n. especial, p. 98-114, maio 2015. ISSN: 1983-9030 


\section{FESTIVALES DE GIMNASIA: PRINCIPIOS DE FORMACIÓN EN VISIÓN DEL ESPECIALISTAS}

\section{RESUMEN}

Festivales de Gimnasia consisten en eventos donde se presentan varias posibilidades gimnásticas dirigidas a la celebración y el intercambio entre los practicantes. El objetivo de este estudio fue analizar los principios educativos y formativos que orientan los festivales gimnásticos por medio de la opinión de profesionales que actúan en la organización de este tipo de evento, buscando además saber cuál es su importancia para la promoción y el mantenimiento de la tradición gimnástica. Para ello se realizó una investigación cualitativa mediante la consulta de nueve voluntarios expertos (Argentina, Brasil, Chile, Dinamarca, España, México, Portugal y la República Checa) a través de un cuestionario semi-estructurado. Los resultados confirman la importancia que tienen los festivales, tanto para el fomento de la gimnasia como para la formación humana, como para el mantenimiento de las tradiciones de gimnasia, el intercambio de experiencias (técnicas y estéticas), el intercambio cultural y en la valoración de la participación, del voluntariado y de la colectividad.

Palabras-Clave: Festival; Gimnasia; Formación; Tradición; Educación. 


\section{INTRODUÇÃO}

Os festivais ginásticos são eventos cujos objetivos variam em função do local, dos organizadores, das tradições e de outros diversos aspectos. Conforme a definição oferecida pelo Novo Dicionário Aurélio da Língua Portuguesa ${ }^{1}$, o termo festival pode ser entendido como "série de acontecimentos e/ ou espetáculos artísticos, esportivos, etc." também anunciado como "grande festa". Contudo, independente do objetivo que possuem, sua importância parece ultrapassar o âmbito ginástico permitindo aproximações tanto no âmbito formativo como no institucional e social.

Um festival não se limita às atividades ou à programação oficial, oferece também uma esfera de experiências, é um mundo de novos conhecimentos e vivências, como dividir alojamento, ter acesso à visão ginástica de outros países, conhecer novas pessoas e novas culturas, entre outras oportunidades. A intensidade e a riqueza vivida em cada evento podem variar significativamente, mas em geral promove aprendizagens que ultrapassam o ideal de apresentar uma coreografia.

O objetivo deste trabalho foi discutir os princípios pedagógicos e formativos que norteiam os festivais ginásticos, bem como a importância dos mesmos para a manutenção da tradição e da cultura ginástica na opinião dos profissionais de grande experiência na coordenação, organização e participação neste tipo de evento.

Como é possível perceber, partimos do pressuposto que os festivais contribuem na formação de cada um de seus participantes, logo, conhecê-los de modo mais aprofundado nos parece um objeto de suma importância, tanto para estudiosos da ginástica como para a Educação Física como um todo.

Finalmente, esperamos que o debate aqui apresentado colabore para a melhor compreensão da importância dos mesmos entre ginastas, professores, gestores e demais envolvidos neste campo do conhecimento, considerando que muitos eventos são 
realizados com uma grande dimensão formativa e com diversas contribuições para a área.

A opinião dos especialistas foi obtida por meio de questionários semiestruturados, enviados por meio eletrônico (via e-mail), respondidos e devolvidos também eletronicamente. Este procedimento foi adotado considerando a distância dos sujeitos bem como a agilidade no tempo de resposta. Junto ao questionário foi enviado um Termo de Consentimento Livre e Esclarecido (TLCE) que foi impresso, assinado, escaneado e devolvido também eletronicamente ${ }^{1}$.

Segundo Oliveira $^{2}$ pesquisas como estas, tem a capacidade de apresentar a complexidade de uma pressuposição, avaliar a influência mutua das variáveis, entender e qualificar os resultados, e assim mostrar os subsídios no processo de construção de opiniões dos grupos, admitindo a interpretação das particularidades dos indivíduos.

Assim sendo, o referido estudo consultou, por meio de um questionário aberto, treze sujeitos, escolhidos segundo o critério de representatividade na área da ginástica e comprovada experiência como participante (coordenador de grupo) ou organizador de festivais ginásticos. Por motivos éticos, os nomes dos entrevistados foram substituídos por pseudônimos. Obtivemos nove respostas dos treze questionários enviados, sendo duas de especialistas nacionais e sete internacionais: Argentina, Chile, Dinamarca, Espanha, México, Portugal e República Tcheca. Cabe destacar que o questionário foi elaborado pelos autores e validado por quatro pesquisadores doutores integrantes do Grupo de Pesquisa em Ginástica (GPG) da FEF - UNICAMP. ${ }^{3}$

Para a análise dos dados qualitativos coletados, utilizamos a Análise de Conteúdo nos termos de Bardin. ${ }^{4}$ Conforme esse modelo analítico, a análise de conteúdo é um interessante instrumento no sentido da identificação da diversidade de formas e adaptações do discurso. De acordo com a autora, procedemos com a codificação,

\footnotetext{
${ }^{1}$ Esta pesquisa foi aprovada pelo Comitê de Ética em Pesquisa da Faculdade de Ciências Médicas da UNICAMP.
} CAAE: 07984914.5.0000.5404; Número do parecer: 729.149.

Conexões: revista da Faculdade de Educação Física da UNICAMP, Campinas, v. 13, n. especial, p. 98-114, maio 2015. ISSN: 1983-9030 
seleção e categorização dos dados, fazendo com que os mesmos pudessem ser interpretados segundo os objetivos da pesquisa. Desse modo, categorizar consistiu no processo de agrupamento de elementos que possuíam características em comum conforme cada um dos objetivos perseguidos. No caso deste trabalho, por exemplo, foi importante a busca por dados que elucidassem os valores atribuídos pelos voluntários aos festivais, e particularmente à formação e a participação nesses eventos.

Após o recebimento das respostas, foi realizada a codificação, classificação e a categorização dos dados, para, ao final, proceder com a interpretação do material e a confecção do texto narrativo de síntese, conforme os apontamentos de Souza Júnior; Tavares de Melo e Santiago. ${ }^{5}$

\section{OS FESTIVAIS GINÁSTICOS: BREVE CONTEXTUALIZAÇÃO HISTÓRICA}

A Lingiada possivelmente um dos primeiros festivais ginásticos relatados na literatura, foi realizada na cidade de Estocolmo (Suécia) em homenagem ao criador da Educação Física Sueca, Per Henrik Ling (1776-1839), também fundador da Ginástica Ling ou, mais comumente denominada, Ginástica Suéca. ${ }^{6}$ O festival aconteceu em 1939, com 7.399 participantes vindos de 20 países e, segundo Santos, ${ }^{6}$ além do festival, aconteceu um congresso mundial sobre atividade física, o qual teve a participação de 1.500 instrutores. A segunda Lingiada foi realizada em 1949, porém esta, com a participação de 14.000 ginastas, dobrando o número de participantes em relação à primeira.

Conforme Mechbach e Waneberg, ${ }^{7}$ durante a Assembleia Geral da Federação Internacional de Ginástica (FIG), que aconteceu paralelamente à segunda Lingiada, o holandês Johannes Heinrich François Sommer fez uma proposta para a realização de um festival mundial sob a responsabilidade da FIG. Já na Assembleia de 1951 o festival foi inserido no programa oficial de eventos, com o nome de "Gymnaestrada".

A primeira Gymnaestrada foi realizada em 1953, em Roterdã (Holanda), inspirada nas Lingiadas comentadas anteriormente. Essa primeira edição do evento contou com a 
participação de quase 5000 ginastas de 14 países. $^{6}$ A Gymnaestrada, atualmente denominada World Gymnaestrada (em português - tradução literal Ginastrada Mundial - GM) pode ser considerada na atualidade o mais importante evento internacional de Ginástica Para Todos (GPT), amplamente denominada Ginástica Geral (GG), organizado pela FIG, com uma participação de 55 países, somando um número de participantes duas vezes maior do que os Jogos Olímpicos, isto é, cerca de 19.000 ginastas. ${ }^{8}$ É realizada de quatro em quatro anos, e terá sua XV Edição em 2015 na Helsinque (Finlândia).

Outro tradicional evento de Ginástica e Esportes é até hoje realizado na Alemanha desde 1860. Segundo Oliveira e Stadnik ${ }^{9}$ o Deutsche Turnfest é realizado pelo Deutsche Turn Bund (DTB), uma associação esportiva alemã. O termo Turnfest relaciona-se com a tradição de cultura corporal marcada pela ginástica, mas que se abre também para outras atividades. "Os acontecimentos histórico-social-político-econômico-pedagógicos ocorridos na Alemanha, no século XIX, configuraram uma proposta didáticopedagógica, chamada Turnen." 10

Podemos citar ainda outros importantes festivais internacionais que, da mesma forma que a $G M$, tem atraído à participação de milhares de ginastas e contribuído significativamente ao fomento da Ginástica, e mais especificamente da Ginástica Para Todos colaborando assim para a manutenção das tradições gímnicas e da formação humana. ${ }^{11}$ Dentre eles podemos destacar os seguintes: Landstaevne (Dinamarca), realizado a cada quatro anos há 148 anos pela Associação Dinamarquesa de Esportes e Tiro; O Slets - antigamende denominado Spartaquiadas - que já foi o maior festival do gênero, organizado desde 1882 na República Tcheca, por meio da SOKOL; ${ }^{12}$ O Blume Gran Canaria (Canárias - Espanha), tendo sua primeira edição em 1960; e Sun Svoli na Finlândia, organizado pela Associação Svoli; e mais recentemente o Festival Del Sole (Itália)..$^{3}$

O Brasil por sua vez não possui uma tradição consolidada quando falamos em eventos não competitivos. Logo a trajetória dos festivais ginásticos no âmbito nacional está Conexões: revista da Faculdade de Educação Física da UNICAMP, Campinas, v. 13, n. especial, p. 98-114, maio 2015. ISSN: 1983-9030 
relacionada com o desenvolvimento da GPT no país a partir da década de 1990, embora desde o final do século XIX e até a década de 1970 do século XX, muitos festivais aconteceram devido à influência da tradição germânica (dos clubes alemães de ginástica) e das demonstrações escolares e militares, respectivamente. ${ }^{13}$

$\mathrm{Na}$ história recente, observamos que alguns festivais, os quais contaram com a participação massiva de grupos, estão relacionados com eventos universitários de Ginástica Para Todos. Como exemplo o "Curso Internacional de Ginástica Geral” realizado pela Universidade Estadual Paulista (UNESP- Rio Claro), o qual teve simultaneamente o "Festival Internacional de Ginástica e Dança de Rio Claro", contando com mais duas edições. Assim como os festivais realizados mais recentemente nos Fóruns Internacionais de Ginástica Geral (FIGG) que acontecem desde 2001, realizados pela Faculdade de Educação Física da UNICAMP em parceria com o SESCServiço Social do Comércio e com o apoio da International Sport and Culture Association (ISCA). ${ }^{14}$

Além desses festivais realizados paralelamente a eventos gímnicos, é preciso destacar que em 1982, foi realizado o primeiro festival oficial de Ginástica Geral no Brasil em Ouro Preto (MG), chamado "Fegin” (Festival Nacional de Ginástica), que teve sua continuidade por mais 11 edições. Em 1992, a Confederação Brasileira de Ginástica (CBG) aprovou a realização anual do "Torneio Gymbrasil”, uma espécie de Ginastrada brasileira que substituiu o FEGIN e foi incluído no calendário oficial da entidade. ${ }^{15} \mathrm{O}$ Gymbrasil é organizado por federações estaduais com o suporte da CBG e em 2012, a partir da sugestão do Comitê Técnico de Ginástica Para Todos, teve seu nome alterado para "Festival Gymbrasil". Esse que é ainda o único festival reconhecido oficialmente pela CBG, teve na edição de 2013, a participação de 332 ginastas de 14 grupos representando seis estados, ${ }^{16}$ o que revela que o festival ainda está em desenvolvimento e longe de poder ser considerado um evento de abrangência nacional e massiva.

Desse modo, observa-se que o Brasil ainda não possui um festival nos moldes e com a amplitude dos países Europeus supracitados, mas não podemos deixar de mencionar que Conexões: revista da Faculdade de Educação Física da UNICAMP, Campinas, v. 13, n. especial, p. 98-114, maio 2015. ISSN: 1983-9030 
muitos festivais locais, regionais e até estaduais, como o GINPA realizado pela Federação Paulista de Ginástica (FPG) são realizados periodicamente, contribuindo para a continuidade da prática da ginástica e para sua socialização.

\section{OS FESTIVAIS GINÁSTICOS NA OPINIÃO DOS ESPECIALISTAS}

Este trabalho foi baseado no trabalho de conclusão de curso "Festivais Ginásticos: tradição, cultura, educação e congraçamento". ${ }^{3}$ Vale ressaltar que todos os sujeitos consultados possuíam destacado envolvimento no âmbito da Ginástica e, mais especificamente, ampla experiência em festivais ginásticos; por isso foram considerados "especialistas".

O questionário empregado continha sete questões divididas em duas partes. Parte 1: uma questão de apresentação pessoal, onde o voluntário descrevia sua formação e envolvimento com a Ginástica; Parte 2: seis questões que visavam conhecer a opinião dos mesmos sobre as características e importância dos festivais bem como os valores formativos presentes.

Dos nove sujeitos participantes, seis possuem graduação em Educação Física, todos possuem amplo envolvimento com a Ginástica para Todos bem como participação em ao menos uma edição da GM. Vejamos então, como eles interpretam os festivais, a partir das diferentes dimensões adotadas no presente estudo.

\section{Principais características dos festivais ginásticos}

A característica mais ressaltada foi que os festivais representam um espaço fundamental para apresentações gímnicas, convertendo-se num lugar de intercâmbio de experiências, ideias e conhecimentos técnicos, estéticos e organizativos. Como os festivais em análise não possuem um caráter competitivo, os participantes sentem-se à vontade para explorar e apresentar algumas inovações, recriando-as conforme a particularidade do seu grupo, contribuindo para um "Banco de Ideias""17 coletivo. Ao contrário dos eventos competitivos, vê-se uma maior liberdade de trabalho, em outras palavras: "Para mim a 
maior caracterização de um festival de ginástica é a possibilidade dos grupos apresentarem seus trabalhos sem seguir "regras" [...]" (Especialista 5).

Na opinião do Especialista 1 os Festivais Ginásticos deveriam se caracterizar como uma amostra do que é realizado nas instituições, pois pode existir uma orientação pedagógica a qual os alunos e suas experiências de vida também façam parte da composição coreográfica, desta forma as expressões corporais passam a ter um significado maior.

[...] las instituciones que se caracterizan por una orientación pedagógica deberían mostrar trabajos en que los propios participantes sean los que organizan y preparan sus composiciones coreográficas, transmitiendo en ellas lo que el grupo o institución piensa sobre la Gimnasia, lo que siente y quiere comunicar. Diferente a los grupos más orientados por la técnica que priorizan la estética y generalmente reproducen las indicaciones u orientaciones de los técnicos. (ESPECIALISTA 1)

Estes eventos se relacionam ademais com o ideal de festa, isso é, de encontros que oportunizam a convivência, a coletividade, e a sociabilidade ${ }^{18}$. O caráter participativo esteve presente em quase todos os discursos dos especialistas, mostrando que o mais importante é realmente a participação e a chance de apresentar o melhor de cada um. Uma grande oportunidade para o fomento da diversidade:

Diferentes tipos de composições de movimentos rítmicos, reunião de ginastas de muitos países, o confronto de trabalho criativo em diferentes programas de ginástica geral e abordagens para o desempenho de grupos pequenos e grupos de grande porte. (ESPECIALISTA 9 - Tradução livre dos autores)

\section{Aspectos formativos e educativos associados aos festivais}

Vemos as respostas um significativo destaque para a cooperação, auto-organização, ampliação das experiências pessoais e também, para a formação de novas amizades. Em suas palavras:

Los Festivales son un increíble catálogo de posibilidades gimnásticas. La posibilidad tan abierta de expresar, organizar y crear composiciones coreográficas hace que las aportaciones de todos y cada uno de los grupos sean absolutamente enriquecedoras. (ESPECIALISTA 3)

En todo enfrentamiento deportivo, existe una competitividad, una búsqueda del éxito, la victoria. Ahora bien, en los Festivales de Gimnasia la mayoría de los gimnastas, el aspecto competitivo es una parte más de su formación, como también lo puede ser la socialización, la transmisión de valores como la

Conexões: revista da Faculdade de Educação Física da UNICAMP, Campinas, v. 13, n. especial, p. 98-114, maio 2015. ISSN: 1983-9030 
superación, cooperación, etc., que es lo que se vive en un Festival. (ESPECIALISTA 2)

Entendemos com isso que a possibilidade de troca de experiências, de observação da diversidade cultural e do respeito às mais variadas formas de apresentação ginástica, fazem dos festivais verdadeiros laboratórios para a formação humana. ${ }^{17,19}$

\section{A importância dos festivais no âmbito da ginástica}

As opiniões dos sujeitos salientam alguns aspectos que evidenciam os festivais como ações promotoras da ginástica. Para isso, os grupos devem desenvolver e potencializar a motivação de cada participante; incentivar a prática regular da GPT e do entendimento da não-competição; fomentar a aproximação da Ginástica à população; criar um ambiente onde a integração se faça presente; buscar a melhora sem transformar a qualidade técnica numa obcessão.

\footnotetext{
Ponto de referência, quer como objetivo para o qual se trabalha, potencializando e motivando o desenvolvimento, quer como referência relativamente aos trabalhos apresentados por outros grupos e que podem inspirar novas soluções para outros grupos. (ESPECIALISTA 7)

As performances em si são uma grande inspiração para que todos estejam em um festival de ginástica: instrutores, organizadores, ginastas e espectadores. Pode construir um entendimento comum sobre o que é a ginástica. Além de poder ser a "janela" mais importante para a população - o tempo em um ano, quando jornais, TV e rádio tem foco em nossa atividade (ESPECIALISTA 8 - Tradução livre dos autores).
}

Nesse sentido ainda, e conforme os apontamentos do Especialista 1, os festivais representam um modo de "prestar contas" à sociedade, de mostrar o que cada ginasta, cada grupo ou cada país tem de melhor nesse âmbito. Uma verdadeira oportunidade de aproximar a ginástica à sociedade e de renovar o gosto por sua prática, em tempos onde outras práticas estão sobrepondo-se a ela.

\section{Contribuições dos festivais para a formação dos participantes e dos profissionais envolvidos}

No que se refere a formação em valores dos participantes, os especialistas ressaltaram a ideia de que os festivais são uma manifestação cultural por meio da qual é possível sentir-se parte de um grupo, bem como apreciar a produção de outros, auxiliando na Conexões: revista da Faculdade de Educação Física da UNICAMP, Campinas, v. 13, n. especial, p. 98-114, maio 2015. ISSN: 1983-9030 
construção de um olhar crítico das possibilidades de prática da ginástica. Desse modo, reconhece-se que "[...] la gimnasia con orientación pedagógica privilegia la Formación Humana y no a la Capacitación.” (ESPECIALISTA 1).

Não menos importante, a participação nesse tipo de evento propicia um conjunto de aprendizagens que merece destaque, como sugere o discurso abaixo:

\footnotetext{
[...] o dia do evento pode trazer o aprendizado relacionado a um "ritual" de preparo antes da apresentação como a marcação da coreografia em um espaço diferente do qual se está acostumado a apresentar, quanto ao preparo do figurino, ao preparo dos materiais a serem utilizados, ao preparo do corpo, a concentração necessária, a resolução de pequenos problemas que podem acontecer com o grupo. (ESPECIALISTA 6)
}

Para os profissionais envolvidos na organização de um festival as decisões e o planejamento envolvem, entre outros aspectos, "escolher o local adequado para o evento, captar recursos, materiais, pessoas para trabalhar no mesmo, organizar as inscrições e suas normas, divulgar, definir a programação...” (ESPECIALISTA 6), conformando uma rica experiência no sentido de sua formação profissional, que pode contribuir para sua atuação em outros espaços/âmbitos (escola, universidade, comunidade, ...). Dito de outra forma,

Desde el compartir la tarea con los profesionales y adquiriendo experiencias, revalorizando la socialización, el intercambio o contacto con otras culturas o grupos de pertenencia. (ESPECIALISTA 4)

\section{Motivos para a realização dos festivais ginásticos na contemporaneidade}

Os valores formativos e culturais agregados aos festivais, alguns já mencionados, indicam a pertinência desse tipo de evento social nos dias de hoje. A "possibilidade de apresentação e trocas" foram ressaltadas por vários sujeitos, reconhecendo que os festivais criam um fluxo de informações entre participantes e o público, e fomentando a convivência integrada e diversa (entre gerações - faixas etárias; sexos, nível técnico; diversidade técnica e estética, ...) condição cada vez mais rara numa sociedade acostumada a criar segmentos, dividir em categorias, separar por níveis, e criar espaços de divisão e não de integração. 
Ainda segundo os especialistas, os festivais ginásticos apresentam-se como uma excelente oportunidade para fomentar:

- O gosto pela apresentação pública daquilo que foi produzido de modo íntimo e no seio de um grupo;

- O respeito pela diversidade / diferenças;

- A solidariedade e a integração;

- A criatividade;

- A ginástica como possibilidade de prática;

- O convívio social.

\section{Contribuições dos festivais para a prática e o fomento da ginástica}

De maneira geral, todos os entrevistados relataram ter realizado algum festival, e a maioria encontrou dificuldades como: a falta de uma equipe competente para atuar no comitê organizador, dificuldades financeiras e para o cumprimento dos prazos/cronograma. A dificuldade em localizar e obter suporte para utilizar um espaço com boas instalações, a falta de apoio para divulgação e o baixo reconhecimento institucional, também foram mencionados. Embora sejam muitas as dificuldades para a organização dos eventos com participação massiva, e não competitivos, nos parece que a falta de formação específica, e, principalmente, de cultura para eventos participativos $^{20}$ ainda representem o maior desafio para os profissionais da área.

Por outro lado, em um contexto bem diferente, alguns sujeitos relataram que receberam suporte de instituições públicas e privadas para a realização dos festivais, que em geral são gratuitos e atraem um grande número de expectadores. Um dos entrevistados (Especialista 8), não brasileiro, salientou que em seu país realiza-se uma excelente publicidade do evento e as cidades sedes enxergam a promoção do festival como uma forma de promoção da própria cidade, servindo inclusive para o fomento do turismo da região. 


\title{
CONSIDERAÇÕES FINAIS
}

A performance humana pode ser entendida, segundo Pellegrinotti, ${ }^{21}$ como "a natureza da existência de cada indivíduo”. Assim, cada pessoa, por meio de seus corpos, seus movimentos, sua ação, pode expressar e criar apresentações que por sua vez geram simbolismos de grande interesse pra nossa sociedade. Nas suas próprias palavras:

\begin{abstract}
A atividade física com concepções esportivas de espetáculo e profissionalismo deixa de ser privilégio de alguns para se inserir na vida de todos seres humanos. Nessa direção, a performance passa a ser o referencial poético das realizações humanas dentro da atividade física escolhida pelo indivíduo, sem a necessidade de comparações, mas sim, de satisfação em usufruir com competência e sabedoria sua corporeidade. ${ }^{21}$
\end{abstract}

Desse modo, sentir prazer de exibir suas produções, de mostrar suas habilidades e de revelar o "seu melhor" faz parte da essência humana, seja no trabalho ou no lazer. Essa potencialidade é que torna os festivais (de ginástica, de dança, de música, etc) relevantes para a formação humana. Eventos estes que envolvem multidões, que encantam e que fascinam, unindo os que se interessam por algo semelhante e que expressam uma necessidade de sentir-se realizados de alguma forma.

Por outro lado, Souza ${ }^{19}$ classifica as práticas gímnicas em distintos grupos: competitiva; demonstrativa ou não competitiva; de condicionamento físico; fisioterápicas; e de conscientização corporal. De todas essas possibilidades, a ginástica demonstrativa (GG, GPT), que norteia os festivais ginásticos, é a que tem recebido menor importância das instituições que fomentam a prática da ginástica. E mais, no âmbito dos eventos ginásticos, a ginástica competitiva é a que tem maior projeção na atualidade, tanto do ponto de vista midiático, como financeiro e institucional.

Ao analisar a opinião dos especialistas consultados nessa pesquisa, percebemos que a maioria deles teve experiência no âmbito competitivo, e mesmo assim todos defendem a importância dos festivais de ginástica demonstrativa, principalmente como um meio de prática de lazer e pela relevância que possuem na área formativa e de massificação da ginástica.

Conexões: revista da Faculdade de Educação Física da UNICAMP, Campinas, v. 13, n. especial, p. 98-114, maio 2015. ISSN: $1983-9030$ 
Assim sendo, os valores educativos e formativos dos Festivais Ginásticos ainda podem ser considerados de grande importância para o desenvolvimento formativo dos ginastas, dos profissionais, dos expectadores, dos organizadores e das instituições. De um modo geral, estes eventos contribuem para a manutenção da tradição ginástica, alcançando um amplo conjunto de países, com ou sem tradições seculares no âmbito da ginástica, como é o caso do Brasil. De fato, é possível perceber um crescimento do interesse na prática da Ginástica para Todos - demonstrativa - no cenário nacional, e como indicador desse crescimento podemos citar a participação brasileira na GM, que vem ampliando-se. Na última edição em Lausanne (Suíça), no ano de 2011, alcançou uma expressiva quantidade de 660 pessoas.

Enfim, entendemos que a opinião dos especialistas consultados corrobora os indicadores presentes na literatura, no sentido de mostrar a contribuição "excepcional" dos Festivais Ginásticos para a formação pessoal e profissional.

\section{REFERÊNCIAS}

${ }^{1}$ FERREIRA, A. B. H. Novo Aurélio século XXI: o dicionário da língua portuguesa. 3. ed. Rio de Janeiro: Nova Fronteira, 2010.

${ }^{2}$ OLIVEIRA, M. S. O panorama da ginástica artística masculina brasileira: um estudo histórico-crítico do período 2005-2008. 270 f. 2010. Dissertação (Mestrado em Educação Física) - Faculdade de Educação Física, Universidade Estadual de Campinas, Campinas, 2010.

${ }^{3}$ PATRICIO, T. L. Festivais ginásticos: tradição, cultura educação e congraçamento. 80 f. 2012. Trabalho de Conclusão de Curso (Bacharelado em Treinamento em Esportes) Faculdade de Educação Física, Universidade Estadual de Campinas, Campinas, 2012.

${ }^{4}$ BARDIN, L. Análise de conteúdo. Lisboa: Edições 70, 2011. 
${ }^{5}$ SOUZA JÚNiOR M. B. M.; TAVARES DE MELO, M. S.; SANTIAGO, M. E. A Análise de conteúdo como forma de tratamento dos dados numa pesquisa qualitativa em educação física escolar. Movimento, Porto Alegre, v. 16, n. 3, p. 31-49, jul./set. 2010 .

${ }^{6}$ SANTOS, J. C. E. Ginástica geral: elaboração de coreografias, organização de festivais. Jundiaí: Fontoura, 2001.

${ }^{7}$ MECHBACH, J.; LUNDQUIST WANEBERG, P. The World Gymnaestrada: a noncompetitive event. Scandinavian Sport Studies Forum, v. 2, p. 99-118, 2011.

${ }^{8}$ FEDERAÇÃO INTERNACIONAL DE GINÁSTICA. $14^{\text {th }}$ World Gymnaestrada. Récit d'une Aventure Humaine Exceptionnelle. Association World Gymnaestrada Lausanne 2011. Lausane, 2013.

${ }^{9}$ OLIVEIRA, N. R.; STADNIK, A. M. W. Grandes eventos esportivos: um olhar sobre o contexto europeu e o seu movimento de esporte para todos na atualidade. Motrivivência, ano XVIII, n. 27, p. 19-32, dez. 2006.

${ }^{10}$ TESCHE, L. O turnen, a educação e a educação física nas escolas teutobrasileiras, no Rio Grande do Sul: 1852-1940. Ijuí: Ed. da Unijuí, 2001.

${ }^{11}$ PAOLIELLO, E. Nos bastidores da ginástica geral: o significado da prática. In: PAOLIELLO, E. (Org.). Ginástica geral experiências e reflexões. São Paulo: Phorte, 2008.

${ }^{12}$ BANJAK, S. J. SOKOL gymnastic manual. Slovak: The Slovak Gymnastic Union Sokol, 1993.

${ }^{13}$ QUITZAU, E. A. Educação do corpo e vida associativa: as sociedades ginásticas alemãs em São Paulo (fins do século XIX, primeiras décadas do Século XX). 174 f. Conexões: revista da Faculdade de Educação Física da UNICAMP, Campinas, v. 13, n. especial, p. 98-114, maio 2015. ISSN: 1983-9030 
Dissertação (Mestrado em Educação Física) - Faculdade de Educação Física. Universidade Estadual de Campinas, Campinas, 2011.

${ }^{14}$ BORTOleto, M. A. C.; TOledo, E.; AYOUB, E.; PAOliEllo, E. (Org.). Ginástica: movendo pessoas, construindo cidadania. In: FÓRUM INTERNACIONAL DE GINÁSTICA GERAL, 7., 2014, Campinas. Anais... Campinas: FEF/UNICAMP: SESC, 2014.

${ }^{15}$ SANTOS, J. C. E.; SANTOS, N. G. M. História da ginástica geral no Brasil. Jundiaí: Fontoura, 1999.

${ }^{16}$ CONFEDERAÇÃO BRASILEIRA DE GINÁSTICA (CBG). Festival GymBrasil 2013. Piracicaba: SESC, 2013. (Comitê Técnico de Ginástica Para Todos).

${ }^{17}$ PAOLIELLO, E. et al. Grupo Ginástico Unicamp 25 anos. Campinas: UNICAMP, 2014. 288p.

${ }^{18}$ AYOUB, E. A Ginástica geral na sociedade contemporânea: perspectivas para a Educação Física Escolar. 186 f. Tese (Doutorado em Educação Física) - Faculdade de Educação Física, Universidade Estadual de Campinas, Campinas, 1998.

${ }^{19}$ SOUZA, E. P. M. de. Ginástica geral: uma área do conhecimento da Educação Física. 163 f. Tese (Doutorado em Educação Física), Faculdade de Educação Física, Universidade Estadual de Campinas, Campinas, 1997.

${ }^{20}$ GAJDOŠ A.; PROVAZNIKOVA M.; BANJAK S. J. 150 years of the sokol gymnastics in Czechoslovakia, Czech and Slovak Republic. Science of Gymnastics Journal, Slovakia, v. 4, n. 3, p. 73-82, 2014.

${ }^{21}$ PELLEGRINOT, I. L. Performance humana: vida da vida. In: BATISTA, J. C. F. Ginástica em questão. Ribeirão Preto: Tecmedd, 2006.

Conexões: revista da Faculdade de Educação Física da UNICAMP, Campinas, v. 13, n. especial, p. 98-114, maio 2015. ISSN: 1983-9030 
Contato:

Tamiris Lima Patrício

E-mail: tamirislima90@hotmail.com

Conexões: revista da Faculdade de Educação Física da UNICAMP, Campinas, v. 13, n. especial, p. 98-114, maio 2015. ISSN: 1983-9030 